\title{
Carbon Dioxide Emissions and Carbon Cycle Basics: What Should We Do Next?
}

\author{
Onyr Tutulmaz
}

\begin{abstract}
Climate change and $\mathrm{CO}_{2}$ emissions issue becomes more important in the political agenda every year. Despite the rising effort to curb the emissions little success has been achieved so far. This paper analyzes the severity of the situation bringing the carbon cycle basics into the economic analysis at first hand, stressing once more that the ecological frame should be the bigger macro level borders for the economy. Our analysis sees that there is little chance to reach aimed emissions levels by international endeavor on regulations. Moreover, the severity of the carbon amount already accumulated in the atmosphere and its future results seem to be forcing us to take radical steps about our economy. It can be argued that one of the essential steps to take is to transform energy sector as fast as possible. More than that, other methods to be able to take carbon from the atmosphere and to send the emissions to the underground instead of atmosphere should be taken into account for future.
\end{abstract}

Index Terms - Climate change, $\mathrm{CO}_{2}$ emissions, carbon cycle, Kyoto protocol, ecological economics. JEL Codes: Q53, Q54, Q56, 013 .

\section{INTRODUCTION}

Climate change is one of the most serious problems humanity has encountered so far in its history. Although a great deal of academic, political and international endeavor attributed to tackle that problem a small success has achieved so far. Our study will try to look at the subject in a critical manner.

After the destruction experienced in the World Wars the western world has experienced fast industrial development and expansion. Starting from the 60's, the concern on environmental pressure of the economic development started to attract the society's attention thanks to a few important academic and activist studies. We can count 'Silent Spring' [1], 'The Limits to Growth' [2], 'Our Common Future' (or Brutland Report ${ }^{1}$ ) [3] and the studies of the Club of Rome as significant in this road. The society's concern on various environmental disasters caused by the individual industrial accidents reached its summit with the sudden ozone layer surprise. The clear atmospheric photos that show reduction and destruction of the ozone layer caused a sudden worldwide shock. This shock let a unanimous endeavor which finally let the Montreal Protocol to control CFC (chlorofluorocarbon) emissions which disrupts the ozone layer. Montreal Protocol was the first successful example for

Manuscript received September 4, 2015; revised October 25, 2015

${ }^{1}$ This report is prevalently known as Brutland Report, with the name of the commission chair who is also the former Norwegian Prime Minister.

O. Tutulmaz is with the Department of Economics, Hitit University, 19040 Turkey (e-mail: otutulmaz@gmail.com; onurtutulmaz@hitit.edu.tr). the common attempt for protectionist movements [4] (for more information about Montreal Protocol and its achievements see, [5]). However, for the climate change problem we have more complex situation and so far we do not have a successful track.

There are, of course, many reasons for that lack of success. First of all, the climate change issue had not a clear proof as ozone layer issue had, especially at the beginning. Even though the great majority of the environmentalists and scientists are now agreed that the climate change is real and is a big problem for the world, still some of us are not convinced that is the case. More seriously, it has somehow become a political dispute, especially in North America.

There are a few scientific realities used as arguments in that dispute. For example, the world had been through the different climate era periods in it is geological time ${ }^{2}$. Another fact that, the world and the life on it survived and adapted it when the climate change occurs in geological time scales which is enough long for evolutionary adaptation. As we see here the problem part here is the climate change connected to the human caused global warming, which has been emerging in last 2 centuries by human economic engine and which is estimated to be continuing increasingly. Political and religious dimensions have just served to make the problem more complex.

After first Climate Change Conference in 1979, the Intergovernmental Panel on Climate Change was established in 1988. Long endeavor to realize a solid base to deal with the negative effects of economic development gave its fruits in Rio summit in 1992. Establishing 3 Conventions $^{3}$, it was acknowledged in Rio that the world carrying capacity had been exceeded in various areas. Although there is a connection among the natural regenerative capacities in different areas, the most urgent problem was seen in carbon dioxide emissions because of the climate change problem. The first important step was therefore achieved by founding a convention under United Nations (UN) roof. United Nations Framework Convention on Climate Change (UNFCCC) was accepted in Rio summit and came into force in 1994 becoming the first basic treaty to all subsequent diplomacy to deal with the climate change problem. In this sense Kyoto Protocol was generated as a protocol to the UNFCCC convention becoming the first solid base to struggle with the GHG emissions. Kyoto Protocol was signed by 195 countries

${ }^{2}$ Geological time scale is much longer comparing to the historical time scale. The problem we have today is the average temperature change in relatively very short time caused by human activity. Therefore the problem is sometimes defined as human caused global warming.

${ }^{3}$ These 3 Conventions are: 1- UNFCC, Framework Convention on Climate Change, 2-UNCBD, Convention on Biological Diversity, 3UNCCD, United Nations Convention to Combat Desertification. 
and European Union in 1997 and came into force in 2005. Kyoto Protocol required from the signatory countries to reduce the greenhouse gases $(\mathrm{GHG})^{4}$ emissions $5.2 \%$ below their 1990 emission levels.

Despite this entire endeavor, the success achieved is not even close to create a positive effect in greenhouse effect of emissions. This paper aims to analyze the current structure and speculate about the results and methods to deal with it. Second part tries to analyze the carbon emissions situation which is the most important among GHG emissions in terms of their total impact in greenhouse effect. Third part takes the carrying capacity issue into account. Fourth part evaluates the situation of carbon emission and its effects on the carbon cycle. Fifth part concludes the analysis and speculates about future developments and methods that should be searched for.

\section{CARBONDIOXIDE EMISSIONS}

The global economy, since the beginning of the industrial revolution, has been counting mainly on carbon fuels. Fossil fuels such as oil, coal and natural gas are today still uncontested large scale, except for nuclear, energy sources constituting the significant part powering economy. Under those circumstances, the global economy has ended up with today's huge amount of carbon and other greenhouse gasses (GHG) emissions.

Although other GHG gases have also effect on the climate change, we will take mainly the carbon emissions in this paper for two reasons. First, the scales of the total effects of the other GHG gases are not comparable; and second, the most significant threat posed against the natural cycles is the one effects the carbon cycle.

Carbon dioxide concentration in our atmosphere has raised $40 \%$ [6] to $390.5 \mathbf{~ p p m}^{5}$ in 2011 from 278 ppm its pre-industrial levels at mid-18th century [7], If we take into account that about $30 \%$ of the human-caused carbon dioxide has been absorbed by the oceans ${ }^{6}$ the level of the emissions can be evaluated better. Emissions are not just piling up posing a threat to the climate but also they increasingly pile up in the atmosphere; Figure 1a shows the majority of the $\mathrm{CO}_{2}$ accumulation in the atmosphere has been created in last 60 years.

The Fig. 1 summarizes the most important results of the carbon dioxide emissions. Figure 1a shows the rise of $\mathrm{CO}_{2}$ accumulations in the air in last 50 years in terms of the unit of particles per million (ppm). That the oceans have absorbed a part of the total carbon dioxide emissions causes acidification of oceans, an important side-effect of regenerative activity of

${ }^{4} 6$ of the GHG gases are counted in the Protocol: Carbon dioxide $\left(\mathrm{CO}_{2}\right)$, Methane $\left(\mathrm{CH}_{4}\right)$, Nitrous oxide $\left(\mathrm{N}_{2} \mathrm{O}\right)$, Phosphate flora carbons (PFCs), Hydro flora carbons (PFCs) and Sulfate florat $\left(\mathrm{SF}_{6}\right)$ gases. Some of the GHG are most effective than $\mathrm{CO}_{2}$ but in terms of total effect the most important challenge for the world is coming from the $\mathrm{CO}_{2}$ emissions.

${ }^{5} \mathrm{Ppm}$ : particles per million; ppm is a useful unit used to meter the density of emissions in atmosphere. ppm (ppb, parts per billion, also used depending on the scale of emissions) is the ratio of the number of gas molecules to the total number of molecules of dry air. For example, 300 ppm means 300 molecules of a gas per million molecules of dry air.

${ }^{6}$ Another important result of the carbon emissions, therefore, is the ocean acidification. the globe; and Fig. $1 \mathrm{~b}$ gives the $\mathrm{pH}^{7}$ rise in ocean water in last 20 years as an indication of this acidification.
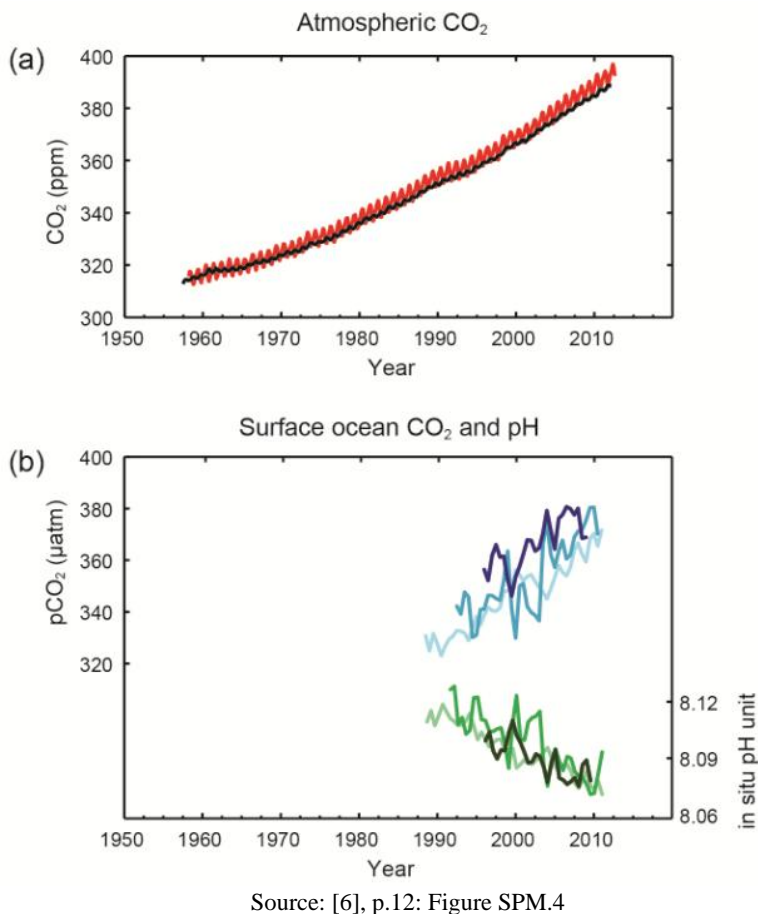

Fig. 1. Multiple observed indicators of a changing global carbon cycle: (a) atmospheric concentrations of carbon dioxide (CO2) from Mauna Loa and South Pole (b) partial pressure of dissolved $\mathrm{CO}_{2}$ at the ocean surface and in situ $\mathrm{pH}$, a measure of the acidity of ocean water. Measurements are from three stations from the Atlantic and the Pacific Oceans

The increase in the GHG amount in the atmosphere increase the heat absorbed by the earth, called greenhouse effect, in unit time period, and it leads an ongoing warming for the globe. This increased heat intake of the globe has caused more than a half $\mathrm{C}$ warming so far. To understand the relationship between the emissions and global warming it is important to understand that the emitted GHG particles in the air will continue the contribute the warming, while they suspend in the atmosphere, by absorbing radiation, even though the new emissions would come to a halt hypothetically. Calculating the long endurance of $\mathrm{CO}_{2}$ in the atmosphere ${ }^{8}$, the existing amount of $\mathrm{CO}_{2}$ would lead a $0.5 \mathrm{C}^{\circ}$ further warming relative to present surface temperature which would mean almost a $1.5 \mathrm{C}$ above the pre-industrial levels (Flannery, 2015). Figure 2 shows the endurance of effects of existing $\mathrm{CO}_{2}$ in the atmosphere. It can be seen from the Fig. 2 that even after eliminating $\mathrm{CO}_{2}$ emissions the temperature rise would continue much longer.

Another perspective we can have on the issue can be about total emissions amount accumulated in atmosphere so far. $555 \mathrm{GtC}^{9}( \pm 85 \mathrm{GtC})$ total $\mathrm{CO}_{2}$ emission has been emitted so far; about $40 \%$ off that amount $(240 \pm 10 \mathrm{GtC})$ has remained in the atmosphere, and the rest is removed by the oceans (about $30 \%$, or $160 \mathrm{GtC}$ ) and cumulative terrestrial natural

${ }^{7} \mathrm{pH}$ is a logarithmic measure of hydrogen ion concentration, used to indicate the acidity or alkalinity of a liquid solution. It shows acidity if $\mathrm{pH}$ is less than 7.

${ }^{8}$ It is calculated that the 15 to $40 \%$ of the Carbon emitted until 2100 will stay in the atmosphere more than 1000 years [7, p.472].

${ }^{9} 1$ Gigatonne of carbon $=1 \mathrm{GtC}=10^{12}$ kilograms of carbon. This corresponds to $3.667 \mathrm{GtCO}_{2}$ 
systems (about $30 \%$, or $155 \mathrm{GtC}$ ) between 1750 and 2011 [7].

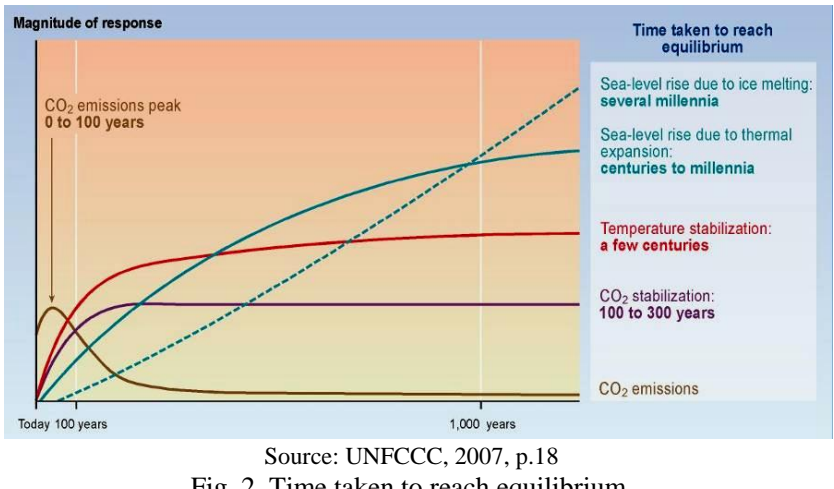

The two third of this emissions released so far is caused from fossil fuel usage since 1750 [7]. The remaining one third has been released by land usage change which includes mainly the effects of deforestation [6].

The world emissions reaching to roughly annual $10 \mathrm{GtC}$ (in terms of nearly $40 \mathrm{GtCO}_{2}$ ) today [8] the cumulative emission of last two and half century can be emitted in only 55 years now. The decrease of the sink capacity and dynamic effects to natural cycles can play as an accelerator effect and should be taken into account.

Another important development in the carbon emissions includes the geographical and nationwide properties of the emissions. While the 2 main emitting parties US and Europe has been trying to slow down its emissions, the developing big economies like China and India, other main emitters, seems to be having acceleration in their emission, and it is expected to happen in short term.

\section{CARRYING CAPACITY}

We have seen that the endeavor and achievement to control carbon emissions have been unsuccessful at curbing the carbon emissions. To build a reference point for emissions first we should clear the regenerative capacity and in wider concept the carrying capacity of the world.

Ecological system of the world contains different natural cycles. As for the carbon cycle, which is directly related with the global warming, there are very differently scaled cycles. For example, geological cycle scaled in thousands of year, photosynthesis cycle takes place on daily basis. Therefore these different scaled cycles should be converted into an annual regeneration capacity.

First of all the regeneration capacity of the world is relatively newly studied area and there is no clear definition for it. Researchers used different terms to describe the regenerative capacities problem of individual cycles such as planetary boundaries [9], Carbon footprint and also they used terms for describing the regenerative capacity in global scale such as carrying capacity and ecological footprints [10].

If we try to describe the regenerative capacity for carbon dioxide emissions, being the directly to the global warming issue, it should be taken into account with other GHG emissions and moreover it should be taken into account as a part of the whole global carbon cycle (see, [7, pp.470-475]).
However, focusing on carbon cycle individually, we can build simplified carbon dioxide emissions and then describe an average rate of it weighted in terms of contribution to global warming. For the sake of simplicity we have tried to isolate the $\mathrm{CO}_{2}$ emissions boundary of the planet below. However we can focus on $\mathrm{CO} 2$ emissions because the positive and negative effects of the aerosol and non- $\mathrm{CO}_{2}$ emissions can currently be assumed to stabilize each other [9, p.10].

\section{A. Threshold Criteria for Carbon Dioxide Emissions}

Based on the extent of land ice, [9] described a dual boundary at $350 \mathrm{ppm}$ for $\mathrm{CO}_{2}$ concentration and $1 \mathrm{Wm}^{-2}$ for radioactive forcing. The present $\mathrm{CO}_{2}$ concentration is around 400 ppm [8].

In terms of carbon footprint, which simulates to the ecological footprint concept, threshold would be 1.0 apparently. Using ecological footprint concept, [11] calculates the carbon dioxide annual regenerative capacity, after separating oceans intake of one third of total $\mathrm{CO}_{2}$ emissions, was exceeded around 16 percent of the unity and constitutes the half of the overall demand. This amount represents very rough calculations around rough assumptions. On the other hand, [12] also gives a similar number saying that after all the carbon fixing activity of the earth, 15 to $30 \%$ of emissions are being accumulated every year in the atmosphere.

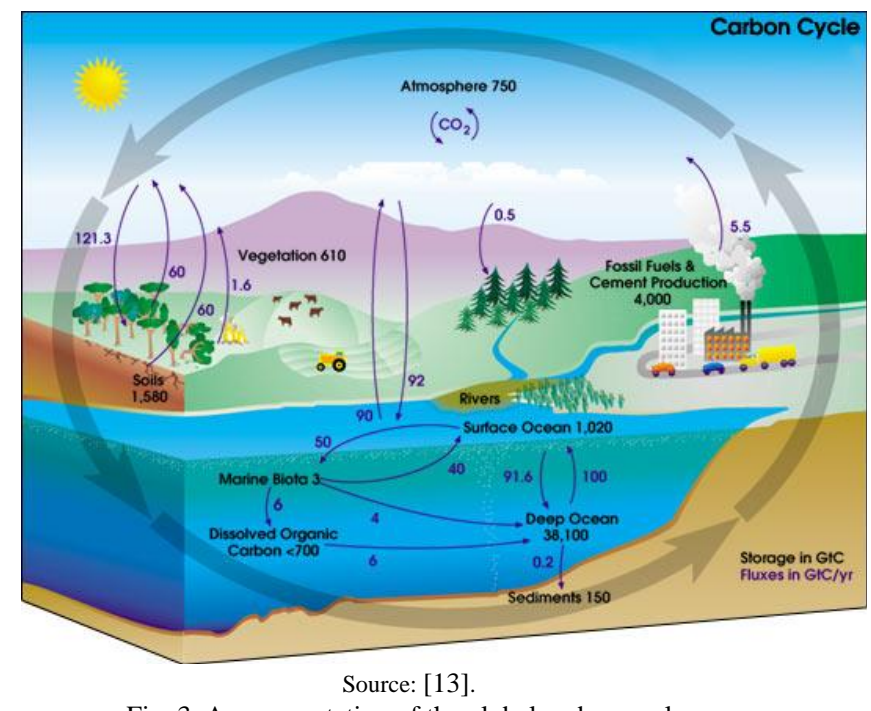

Fig. 3. A representation of the global carbon cycle.

If we look at the carbon fixation capacity closer, the world annually fixes approximately $258^{10} \mathrm{GtCO} 2$ (it is approximately $70 \mathrm{GtC}$ ) via the photosynthesis. About the half of this photosynthesis activity occur in the oceans (47\% of total fixation; it is about $120 \mathrm{GtCO} 2$ or $33 \mathrm{GtC}$ ) and the rest of the photosynthesis carbon fixation is realized by the terrestrial plants and organisms. If we look at the fast carbon cycle, $120 \mathrm{GtC}$ cycled in the terrestrial carbon cycle and about $90 \mathrm{GtC}$ is cycled in the oceans (Figure 3). The carbon cycle includes photosynthesis and other type of carbon sequestration in one part and respiration, decay and other

\footnotetext{
${ }^{10}$ This number does not include the respiration consumption following the photosynthesis; therefore, gross number of carbon fixation can be calculated as higher as much as $40-50 \%$.
} 
emitting causes on the other part. This natural part of the carbon cycle represents the equilibrium of at least a hundred thousand years. What has changed in this equilibrium is the human caused emissions we have been experiencing in last 2 centuries. $10 \mathrm{GtC}$ annual emissions increase the intake part of marine and terrestrial carbon cycle but still more than $40 \%$ of human caused emissions are piling up in the atmosphere (fossil fuel emissions in Figure 3 needs to updated upward).

An important point about this equation of emissions is the intake capacity of the carbon cycle. An increasing intake is the reply of the nature to the emissions and definitely helps to requester a part of human caused carbon emissions. But still the half of that emissions created today`s problem of substantial increase in atmospheric carbon levels, as well as increased acidification in oceans as a side effect. Moreover, if there is a limit to increase this intake capacity, the carbon piling up rates can become a more serious problem in the future than is expected.

\section{B. General Threshold Criteria for the World}

The idea of the ecological footprint is to express the regenerative boundaries of the world better and easier. Therefore the threshold criterion for the global ecosystem must be 1.0 for ecological footprint. As [14] or [10] did, the concept of ecological footprints can be directly connected with the carrying capacity and/or appropriated carrying capacity concepts.

Whereas [9] uses the term of planetary boundaries to define regenerative boundaries of the world. They use 9 planetary boundaries to define global thresholds or "planetary playing fields' as they call.

Wackernagel [11] calculates the 'ecological overshoot' on the regenerative capacity of the biosphere using 6 human activities and finds that human demand overshoots nature's supply by $20 \%$ [11].

\section{Evaluation OF THE HumAn EFFECT ON CARBON CYCLE}

There are several methods used to deal with $\mathrm{CO}_{2}$ emissions and, being connected to it, with the climate change in general. For example cap-and-trade system, carbon tax, carbon credit systems have been used, but their usage is still at the trial level and despite the promising results so far it has been far from bringing significant impact to the carbon emissions.

We have seen that even very mild aims of Kyoto Protocol have not been met. The increasingly recognized effects of climate change force countries to take steps to arise their effects to curb carbon emissions. We have seen valuable effort from developed economies to curb their carbon emissions. Especially these efforts seem accelerated recently: EU prepares to propose $60 \%$ cut at 2050 [15]; US propose $30 \%$ cut 2025 and China undergoes significant promises [16]. Those endeavors definitely can change the unsuccessful route the Kyoto Protocol has taken so far. On the other hand, it is expected that the developing economies' part to be rise and overtake the dominance in the global emissions. This will be another difficulty for the efforts to control the carbon emissions.

Becoming clear of the severity of the climate change situation, global institutions are stepping in and especially the developed economies announcing significant thresholds for their economies. However, newly applied strategies and the complexity of applying international targets create vulnerability for its success. More importantly even if the successful scenario case of emission reductions can be achieved its meaning for global warming is being questioned by some researchers.

More importantly, our basic analysis on carrying capacity and carbon cycle shows that the problem is bigger than about controlling and easing the emissions now. Above the $40 \%$ of the human caused emissions are continuing to pile up in the atmosphere. Accumulation of the human caused emissions increased the carbon levels in the atmosphere by about $45 \%$ percent, from $289 \mathrm{ppm}$ to almost $400 \mathrm{ppm}$ in terms of density, or $550 \mathrm{GtC}$ to $800 \mathrm{GtC}$ in terms of total sink accumulation in the atmosphere.

It is obvious that the world cannot continue to keep emitting carbon to the atmosphere. Whatever the results of the Kyoto Protocol the world might have to change the energy structure in very short time of span.

It must be also stressed that the slower or enduring effects of the emissions and other global boundaries are not often taken into account. Ref. [9] propose that under the second case the expected results of the global warming can increase from $3 \mathrm{C}$ to $6 \mathrm{C}$ at the end of the century.

The endeavor of decreasing carbon emissions is sometimes called as decarbonization. Decarbornization is defined as declining carbon intensity ratio of primary energy by the [17]. However the practice so far has been focus on the decrease by the changing combination of fossil fuels (and forcing out the dirty sources and technologies out) but not to decrease total percentage of the fossil fuels usage or phasing out fossil fuels replacing with nonemission sources. We will separate those two tracks; and calling the former as channel 1 and the latter channel 2, we will separate decarbonization methods. Our stress about running the second channel is not about the limited mitigation but more about the real transformation of the energy sector.

\section{CONCLUSION AND SPECUlation ON What to Do}

The world has encountered an important challenge in the result of last two centuries human activity. Important steps have been taken to control carbon emissions. Although very little success has been achieved so far in terms of carbon emissions reduction regarding the Kyoto Protocol, developed countries started to take important initiative and proposing important reductions (see Part 4).

On the other hand, the structure of emissions shows us a significant rise in average surface temperature is inevitable for our century. Moreover, apart from the success of emission reductions, regarding the present accumulation levels of carbon in the atmosphere, it seems that there is a necessity of radical transformation for the energy sector in near future. This acceleration of second channel, as we call it, will probably soon turn to be an inevitably clear step for the world to take. Consequently, the countries going to be ready for this transformation sooner might have big opportunity. Actually, we have seen the signs of the starting of a big competition in 
this field called green economy and green energy.

Analyzing the situation we can speculate that the first channel, despite its being necessary for the future usage of carbon fuels, an important energy source for humanity, is not the answer the world looks for to deal with the climate change. The second channel, decarbonization by transformation as we propose, will be the next big transition of global economy. Furthermore, we can speculate that even the important second channel might not be enough to deal with the climate change problem when we think about time constraint; therefore, the carbon capturing methods to draw carbon from the atmosphere and emission catching methods for ongoing emissions, which can accommodate a restricted fossil fuel combustion for its future use, should be brought in the world agenda as the third channel in climate change struggle.

\section{REFERENCES}

[1] R. Carson, Silent Spring, Boston, MA:Houghton Mifflin, 1962.

[2] D. H. Meadows, D. L. Meadows, J. Randers, and W. Behrens, The Limits to Growth, New York: Universe Books, 1972.

[3] WCED- World Commission on Environment and Development, Our Common Future, New York: Oxford University Press, 1987.

[4] EC, The Montreal Protocol, European Commission, Belgium, 2007.

[5] UNEP. (2015). The montreal protocol on substances that deplete the ozone layer. UNEP Ozone Secretariat. [Online]. Available: http://ozone.unep.org/en/treaties-and-decisions/montreal-protocol-sub stances-deplete-ozone-layer

[6] IPCC, Summary for Policymakers. In: Climate Change 2013: The Physical Science Basis. Contribution of Working Group I to the Fifth Assessment Report of the Intergovernmental Panel on Climate Change, Cambridge University Press, Cambridge, United Kingdom and New York, NY, USA, 2013

[7] P. Ciais, C. Sabine, G. Bala, L. Bopp, V. Brovkin, J. Canadell, A. Chhabra, R. DeFries, J. Galloway, M. Heimann, C. Jones, C. Le Quéré, R. B. Myneni, S. Piao, and P. Thornton, Carbon and Other Biogeochemical Cycles. In: Climate Change 2013: The Physical Science Basis, Contribution of Working Group I to the Fifth Assessment Report of the Intergovernmental Panel on Climate Change Cambridge University Press, Cambridge, United Kingdom and New York, NY, USA, 2013.

[8] T. Flannery. (2015). A 'Third way' to fight climate change. The New York Times. [Online]. Available: http://www.nytimes.com/ 2015/07/24/opinion/a-third-way-to-fight-climate-change.html?ref=top ics

[9] J. Rockstrom, W. Steffen, K. Noone, A. Persson, F. S. Chapin et al. (2009). Planetary boundaries: Exploring the operating space for humanity. Ecology and Society. [Online]. 14(2). Available: http://www.ecologyandsociety.org/vol14/iss2/art32

[10] H. E. Daly and J. Farley, Ecological Economics: Principles and Applications, Island Press, Washington, DC

[11] M. Wackerngel, N. B. Schulz, D. Deumling, A. C. Linares, M. Jennkins, and V. Kapos et al., "Tracking the ecological overshoot of the human economy," PNAS, vol. 99, no. 14, pp. 9266-9271, 2002.

[12] UNEP. (2011). Introduction to UNFCC \& Kyoto protocol. [Online]. Available:

https://www.google.com/url?sa=t\&rct=j\&q=\&esrc=s\&source=web\&c $\mathrm{d}=1 \&$ ved=0CCAQFjAAahUKEwj2uaGwm4HIAhXMEywKHTaDA SA\&url=http $\% 3 \mathrm{~A} \% 2 \mathrm{~F} \% 2 \mathrm{Fwww} . u n e p . f r \% 2 \mathrm{Fshared} \% 2 \mathrm{Fpublications}$ \%2Fcdrom\%2FDTIx0899xPA\%2Fsession04_UNFCCC.ppt\&usg=AF QjCNGKvJ_aOWjWGcpZ9vkJzSJup3jEQA\&sig2=GUVwW2myCT Q8YRqqEikJTg

[13] NASA. (2011). The carbon cycle: Feature Articles, NASA the Earth $\begin{array}{lll}\text { Observetory. } \quad \text { [Online]. Available: } & \end{array}$ http://earthobservatory.nasa.gov/Features/CarbonCycle/carbon_cycle2 001.pdf

[14] P. Rees, "Ecological footprints and appropriated carrying capacity: What urban economics leaves out," Environment and Urbanization, vol. 4 , no. $121,1992$.

[15] A. Neslen. (2015). EU wants Paris climate deal to cut carbon emissions $60 \%$ by 2050. The Guardian. [Online]. Available: http://www.theguardian.com/environment/2015/feb/23/eu-wants-paris -climate-deal-to-cut-carbon-emissions-60-by-2050

[16] A. Parlapiano, Climate Goals Pledged by China and the U.S., The New York Times, 2014

[17] IPCC, Contribution of Working Group III to the Fourth Assessment Report of the Intergovernmental Panel on Climate Change, Cambridge University Press, Cambridge, United Kingdom and New York, NY, USA, 2013.

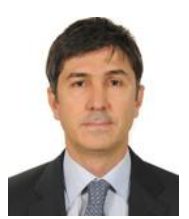

O. Tutulmaz received his $\mathrm{BcS}$ in engineering, $\mathrm{MS}$ and $\mathrm{PhD}$ in economics at METU, Ankara University and Hacettepe University respectively.

He has been in Universita Degli Tor Vergata, Rome in since 2008 and York University, Toronto in Nov. 2010 as a researcher. He conducted his post-doc research in York University from 2012-2013. He worked for WB development project in Kyrgyzstan and Russia in from 2009-2010. He gave lectures in Vistula University, Warsaw in 2014 and 2015 as a visiting lecturer. He currently works for Department of Economics, Hitit University. 